NASA Technical Memorandum 106175 Army Research Laboratory AIAA-93-2297

ARL-TR-9

\title{
Generation of Helical Gears With New Surfaces, Topology by Application of CNC Machines
}

F.L. Litvin, N.X. Chen, and C.L. Hsiao The University of Illinois at Chicago Chicago, Illinois

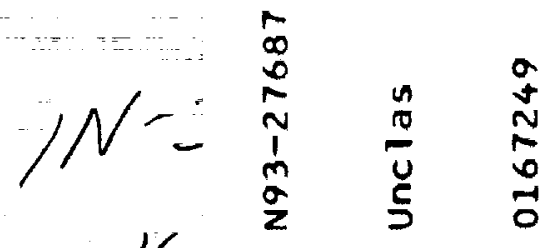

and

R.F. Handschuh

U.S. Army Vehicle Propulsion Directorate

Lewis Research Center

Cleveland, Ohio

Prepared for the

29th Joint Propulsion Conference and Exhibit cosponsored by the AIAA, SAE, ASME, and ASEE Monterey, California, June 28-30, 1993

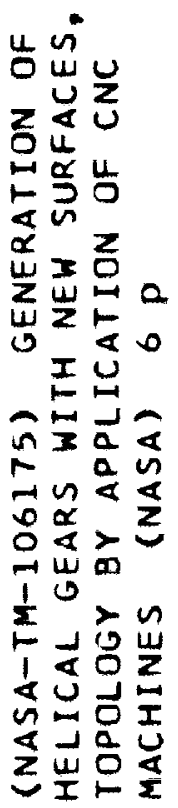




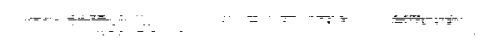




\title{
GENERATION OF HELICAL GEARS WITH NEW SURFACES TOPOLOGY BY APPLICATION OF CNC MACHINES
}

\author{
F. L. Litvin, N. X. Chen, C. L. Hsiao \\ (The University of Illinois at Chicago) \\ and \\ R. F. Handschuh \\ U.S. Army Vehicle Propulsion Directorate \\ (NASA Lewis Research Center)
}

\begin{abstract}
Analysis of helical involute gears by tooth contact analysis shows that such gears are very sensitive to angular misalignment that leads to edge contact and the potential for high vibration. A new topology of tooth surfaces of helical gears that enables a favorable bearing contact and a reduced level of vibration is described. Methods for grinding of the helical gears with the new topology are proposed. A TCA program for simulation of meshing and contact of helical gears with the new topology has been developed. Numerical examples that illustrate the proposed ideas are discussed.
\end{abstract}

\section{Introduction}

Computations by tooth contact analysis (TCA) has shown that involute helical gears are sensitive to errors such as the crossing of gear axes (instead of being parallel) and lead errors. The above errors cause the shift of the bearing contact to the edge and transmission errors of an undesirable shape (figs. 1 and 2). The transfer of meshing of gears with such transmission errors is accomplished with a jerk, producing high vibration and noise.

A new topology of tooth surfaces has been proposed [1-3] that provides for a more favorable bearing contact and transmission error motion even with misalignment present. The generation of the proposed gear tooth surfaces was based on application of existing equipment for generation of helical gears that provided linear relations between the rotations and displacements of the tool and the gear being generated. The modified gear tooth surfaces proposed in the works above could be generated as formate cut by a tool of large dimension or generated point by point if computer controlled. These methods of generation have some difficulties for manufacturing but may be overcome by the new approach.

The new approach that is discussed by the authors is based on application of CNC machines with five degreeof-freedom that enable to provide : (i) computer controlled nonlinear functions that relate the motions of the tool and the gear being generated, (ii) a varied plunge of the tool along the shortest center distance between the axes of the tool and the pinion, and (iii) a point contact of tooth surfaces that is spread over an elliptical area of controlled dimensions. This approach allows to avoid an edge contact and reduce the sensitivity of the gears to misalignment. The generation of gear tooth surfaces may be accomplished by form-grinding.

The new form-grinding method for helical gears that is proposed provides : (i) a stabilized bearing contact, (ii) better conditions of lubrication, and (iii) a predesigned parabolic function of transmission errors that is able to absorb an almost linear function of transmission errors caused by gear misalignment. It is expected that the new topology of the gears will eliminate edge contact and substantially reduce noise and vibrations.

The proposed form-grinding requires the application of a computer numerical controlled ( $\mathrm{CNC}$ ) machine with five degrees-of-freedom, but only four require control by computer. Each tooth space is generated separately, and indexing is required.

\section{Bearing Contact and Transmission Errors of Misaligned Involute Helical Gears}

The authors have developed a TCA program for conventional involute helical gears that permits the investigation of the impact of misalignment. Figs. 1 and 2 show that due to the crossing angle $\Delta \gamma=-5$ arc-min, the contact is shifted to the edge and the transmission errors have the shape shown in fig. 2. Similar results are caused by the lead error $\Delta \beta_{1}=-5$ arc-min.

The edge contact reduces the load capacity of the gears. The transmission errors of the type shown in fig. 2 will inevitably cause premature failure along with an increased vibration and noise. 


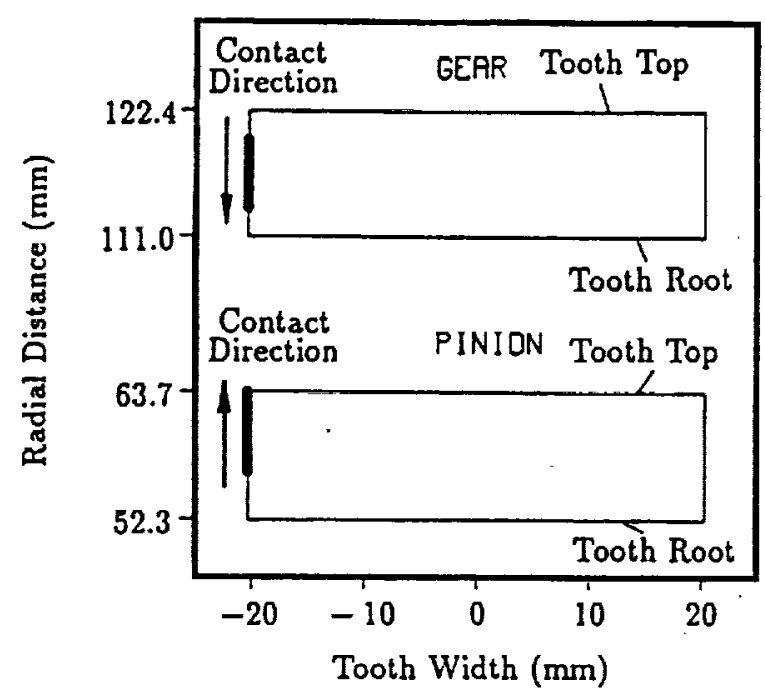

Fig. 1. Edge Contact Due to Axis Misalignment (Crossing Angle, $\Delta \gamma,-5$ arc-min).

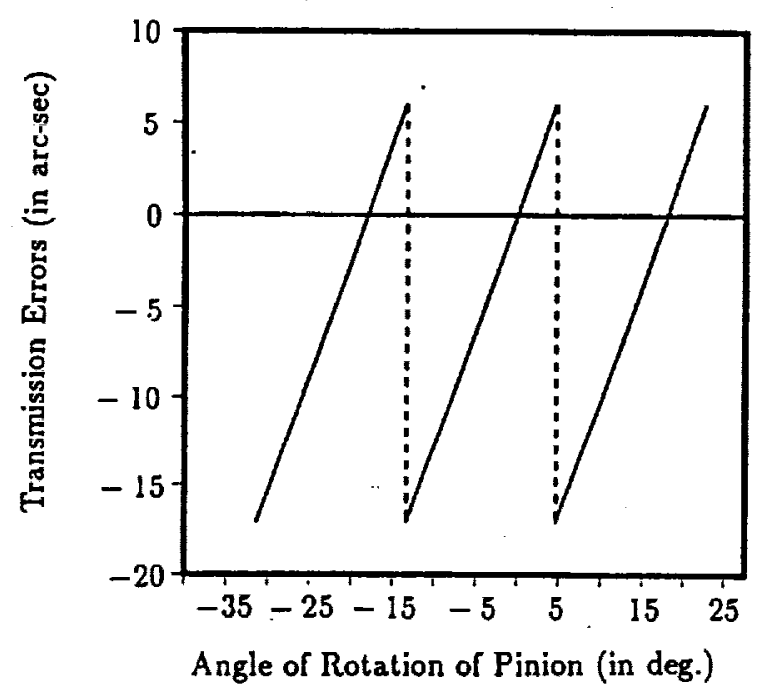

Fig. 2. Transmission Errors of Involute Helical Gears with Axis Misalignment (Crossing Angle, $\Delta \gamma,-5$ arc-min).

\section{New Method for Grinding, Modified Topology}

Pinion Form-Grinding The form-grinding process for the pinion with the new lopology is based on the following ideas :

(i) Consider initially that both tooth sides of the pinion are conventional screw involute surfaces. Using the approach developed in theory of gearing [4], it is possible to delermine the surfaces of a disk-shaped grinding tool that will generate the conventional screw involute surfaces. The tool performs the serew motion wilh respect to the pinion being gencrated. (ii) The grinding wheel surface is modified in the axial section. The deviations of modified tool surface from the conventional one is represented at the mean contact point by a parabolic function, which can be controlled to adapt to different applications. Both pinion tooth sides can be ground simultaneously. The surface of the pinion grinding wheel is a surface of revolution.

(iii) The modified grinding wheel must perform two motions with respect to the pinion : (a) the conventional screw motion, and (b) an additional but varied translational motion along the shortest distance between the axes of the grinding wheel and the pinion. This translational motion presents plunging of the grinding wheel into. the space, being deeper at the edges and less in the middle of the tooth width.

(iv) Using the methods developed in the theory of gearing [4], it becomes possible to determine analytically the equations of the pinion generaled as described above. These equations are necessary for the TCA that has to be applied for simulation of meslinig and contact of helical gears with modified topology.

Gear Grinding Consider that a conventional involute helical gear is in mesh with the pinion whose tooth surface is modified as described above. Such a gear train if not misaligned will transform rotation with negligible transmission errors. The bearing contact of gear tooth surfaces is localized since the gear tooth surfaces are in point contact at every instant due to modification of the pinion tooth surface described above.

The goal is to keep the surface point contact but to provide a predesigned parabolic function of transmission crrors. Such a function is able to absorb a linear discontinuous function of transmission errors caused by angular errors of misalignment. The goal above can be achieved by proper modification of gear tooth surface that is based on the following considerations:

(i) Consider that an imaginary rack-cutler is simultaneously in mesh with the pinion and gear provided with conventional screw involute tooth surfaces. The pinion and the gear perform rotational motions and the rack performs translational motion $s_{q}$ described as follows

$$
\begin{gathered}
s_{1}=r_{1} \phi_{1}=r_{2} \phi_{2} \\
\phi_{2}=\phi_{1} \frac{N_{1}}{N_{2}}
\end{gathered}
$$

where $r_{1}$ and $r_{2}$ are the pinion-gear centrodes, $N_{1}$ and $N_{2}$ are the looth numbers.

Obviously, the transmission function $\phi_{2}\left(\phi_{1}\right)$ is a linear one, and the gears will be sensitive to angular errors of misalignment.

(ii) We may consider now that while the rack performs translational motion $s_{t}$, the pinion rotales through the angle $\phi_{1}=\frac{s_{1}}{r_{1}}$, but the gear rotates through the angle 


$$
\phi_{2}=\frac{s_{t}}{r_{2}}+\Delta \phi_{2}\left(\phi_{1}\right)
$$

where

$$
\Delta \phi_{2}\left(\phi_{1}\right)=a \phi_{1}^{2}, \quad-\frac{\pi}{N_{1}} \leq \phi_{1} \leq \frac{\pi}{N_{1}}
$$

is a parabolic function of the period of cycle of meshing determined as $\phi_{1}=\frac{2 \pi}{N_{1}}$.

Obviously, the transmission function of the pinion and gear generated as described above is determined as

$$
\phi_{2}\left(\phi_{1}\right)=\phi_{1} \frac{N_{1}}{N_{2}}+a \phi_{1}^{2}
$$

where $a \phi_{1}^{2}$ is the predesigned parabolic function of transmission errors.

(iii) The nonlinear transmission function (5) exists even in the case when the gear train is aligned. The advantage of such a function is the ability to absorb a linear but discontinuous function $b \phi_{1}\left(0 \leq \phi_{1} \leq \frac{2 \pi}{N_{1}}\right)$ that is caused by gear misalignment. This is based on the fact $[1,5]$ that the sum of functions represented as

$$
\Delta \phi_{2}\left(\phi_{1}\right)=a \phi_{1}^{2}+b \phi_{1}
$$

can be transformed into the parabolic function

$$
\Delta \phi_{2}\left(\phi_{1}^{\star}\right)=a\left(\phi_{1}^{\star}\right)^{2}
$$

Parabolic functions $\left(a \phi_{1}^{2}\right)$ and $\left(a\left(\phi_{1}^{*}\right)^{2}\right)$ have the same slope. Transformation of function (6) into function (7) is equivalent to coordinate transformation when the coordinate system $\left(\phi_{2}, \phi_{1}\right)$ is translated keeping the orientation of coordinates axes.

(iv) We have assumed above that the pinion tooth surface is a conventional involute screw surface $\Sigma_{1}$. In reality, the pinion tooth surface $\Sigma_{1}^{*}$ is a modified one as mentioned above. However, a synthesized function of transinission errors of parabolic type exists in the case of modification of the pinion tooth surface as well. This statement is based on the fact that surfaces $\Sigma_{1}$ and $\Sigma_{1}^{\star}$ are in tangency at the mean point and only slightly deviate along the helix on $\Sigma_{1}$ that passes through the mean point.

(v) The described above methods of modification of tooth surfaces $\Sigma_{1}$ and $\Sigma_{2}$ enable to localize the bearing contact of $\Sigma_{1}$ and $\Sigma_{2}$ and provide a predesigned parabolic type of transmission errors to absorb the undesired linear function caused by gear misalignment.

(vi) There are alternative methods for grinding of the modified gear tooth surface other than the form-grinding method proposed here. The generation can also be achieved by either a grinding plane or by a grinding worm. However, a nonlinear function that relates the motions of the grinding wheel and the gear being generated is required for both alternative cases.

\section{TCA for Helical Gears with New Topology}

A TCA computer program to simulate the meshing and contact of the gears with the new topology has been developed.

The computations have been performed for a drive with the following design parameters:

$N_{1}=20, \quad N_{2}=40, \quad P_{n}=0.19685 \frac{\mathrm{l}}{\mathrm{mm}}, \quad \alpha_{n}=$ $20^{\circ}, \beta_{p}=30^{\circ}$, and tooth face width $F_{\nu}=40.64 \mathrm{~mm}$.

Two types of path of contact can be provided as shown in figs. 3 and 4 . These two types of path of contact can be obtained by the control of modification of the topology of pinion-gear tooth surfaces in the longitudinal and profile directions.

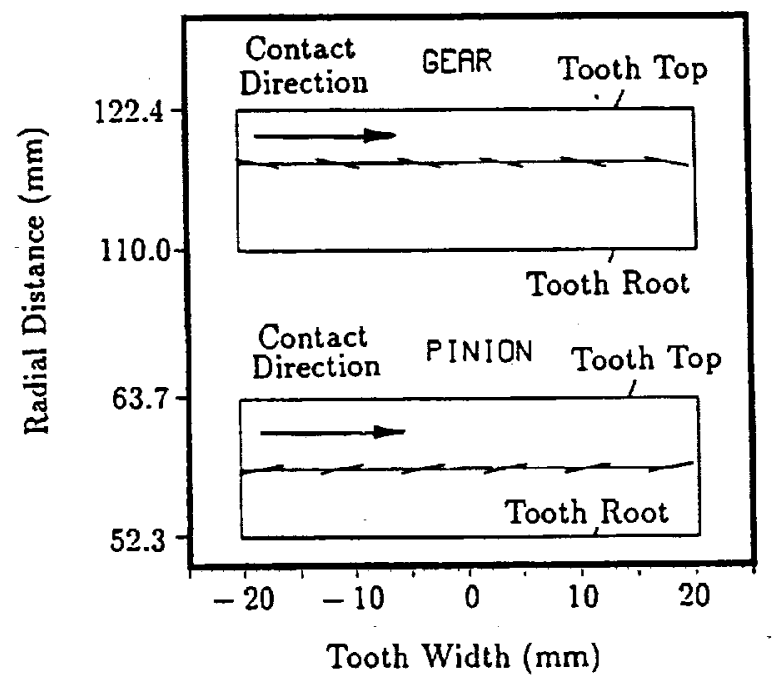

Fig. 3. Latitudinal Contact Path with Shaft Misalignment $\left(\Delta \gamma=-5^{\prime}\right)$.

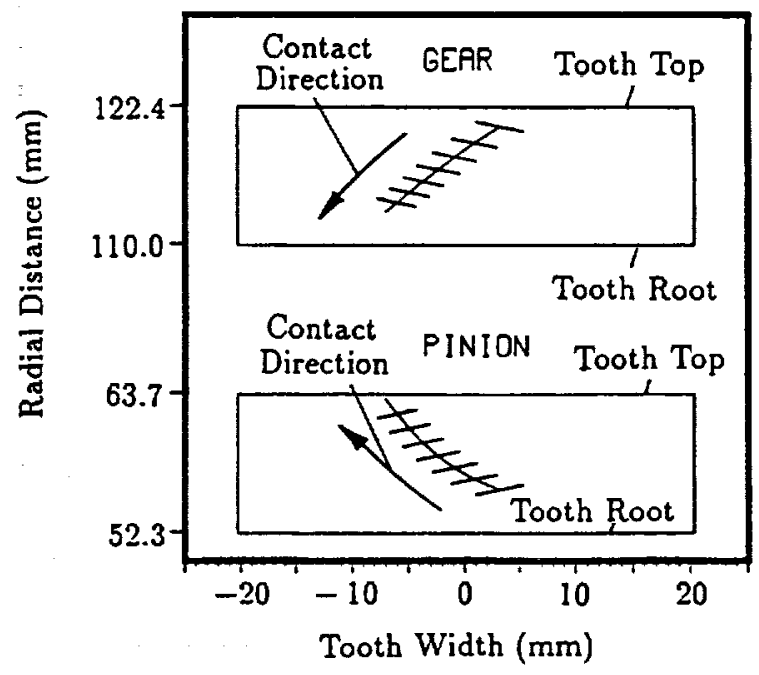

Fig. 4. Longitudinal Contact Path with Shaft Misalignment $\left(\Delta \gamma=2^{\prime}\right)$. 
Thie influence of the crossing angle $\Delta \gamma$ is shown for the above data in figure 5.

The results of investigation show that the alinost linear function of transmission errors caused by misalignment of conventional involute helical surfaces (shown in figure 5) is indeed absorbed by the parabolic type of transmission errors for the modified surfaces (fig. 6).

The major axis of the contact ellipse, under an assumed light load, has been determined as shown in figs. 3 and 4. The undesirable displacement of the path of contact to the bottom and the top of the gear tooth can be controlled by the modification of the surface of the grinding wheel for the pinion generation.

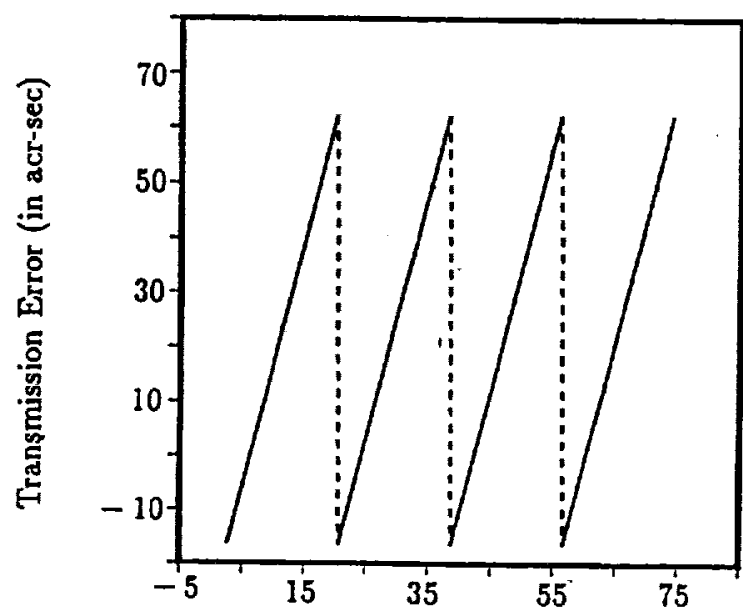

Angle of Rotation of Pinion (in deg.)

Fig. 5. Influence of Misalignment on Transmission Errors $\left(\Delta \gamma=-5^{\prime}\right)$.

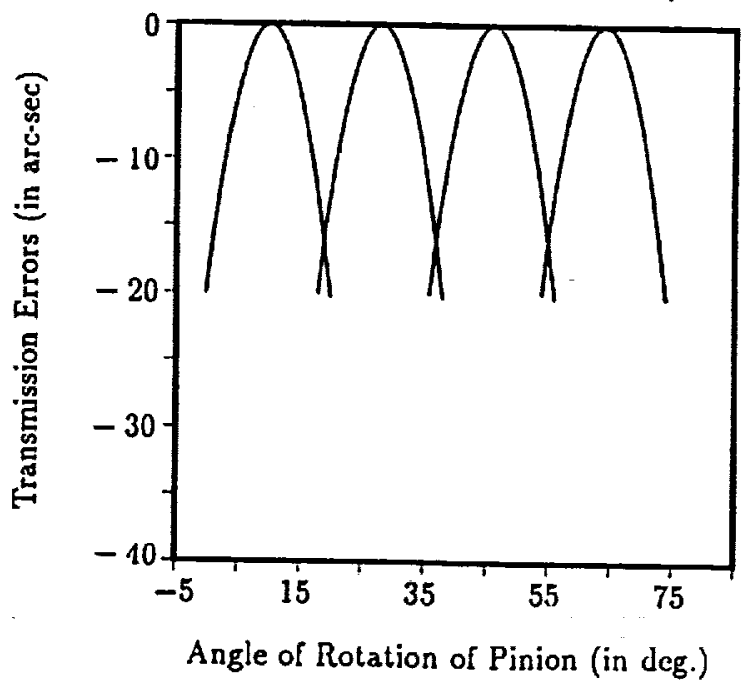

Fig. 6. Influence of Misalignment on Transmission Errors of Helical Gears with New Surface Topology $\left(\Delta \gamma=-5^{\prime}\right)$.

\section{Conclusion}

The following conclusions of the shudy conducled in this paper are as follows :

1. A TCA program for simulation of meshing and contact of conventional involute helical gears has been developed. This program has shown that such gears are very sensitive to angular misalignment and high vibration is inevitable.

2. A new topology of helical gear looth surfaces has been developed. Methods for grinding tooth surlaces have been developed. The bearing contact of gears with the proposed lopology is localized and the transmission errors are reduced.

3. The TCA program for helical gears with the new topology has been developed. The influence of crossing angle on the location of the path of contact and on the transmission errors has becn investigated.

\section{References}

1. F. L. Litvin, J. Zhang, R. F. Ilandschuh and J. J. Coy, "Topology of Modified Ilclical Gears", Surlace Topology, pp. 41 - 58, March, 1959.

2. F.L. Litvin, J. Zlıang, R. F. Handscliuh, and J.J. Coy, "Topology of Modified llelical Cears", NASA TM 102 134, April, 1989.

3. F. L. Litvin and J. Zhang, "Topology of Mlodified llelical Gears and Tooth Contact Analysis (TCA) Program", NASA CR 4224, April 1889.

4. F, L. Litvin, Theory of Gearing, NASA Reference Publication 1212, 1989.

5. D. P. Townsend, Dudley's Gear Ilaudbook, Chapter 1: Theory of Gearing and Application, by F. L. Litvin, pp. 1.1 - 1.13, Sccond Ed., McCiraw-llill, Inc.; New York, 1991. 
Public reporting burden for this collection of information is estimated to average 1 hour per response, including the time for reviewing instructions, searching existing data sources, gathering and maintaining the data needed, and completing and reviewing the collection of information. Send comments regarding this burden estimate or any other aspect of this collection of information, including suggestions for reducing this burden, to Washington Headquarters Senvices, Directorate for Information Operations and Reports, 1215 Jeller
Davis Highway, Suite 1204, Arlington, VA 22202-4302, and to the Office of Management and Budget. Papenwork Reduction Project (0704-0188). Washington, DC 20503.

\begin{tabular}{l|l} 
1. AGENCY USE ONLY (Leave blank) & 2. REPOAT DATE \\
May 1993
\end{tabular}

3. REPORT TYPE AND DATES COVERED

4. TILE AND SUBTITLE

Technical Memorandum

Generation of Helical Gears With New Surfaces, Topology by Application of CNC Machines

6. AUTHOR(S)

WU-505-62-10

1L162211A47A

F.L. Litvin, N.X. Chen, C.L. Hsiao, and R.F. Handschuh

7. PERforming ORganzation NAME(S) AND ADDRESS(ES)

NASA Lewis Research Center

5. FUNDING NUIMBERS

Cleveland, Ohio 44135-3191

and

Vehicle Propulsion Directorate

U.S. Army Research Laboratory

Cleveland, Ohio 44135-3191

9. SPONSORING/MONITORING AGENCY NAME(S) AND ADDRESS(ES)

National Aeronautics and Space Administration

Washington, D.C. 20546-0001

and

U.S. Army Research Laboratory

Adelphi, Maryland 20783-1145

8. PERFORIING ORGANIZATION

REPORT NUWBER

E-7875

11. SUPPLEMENTARY NOTES

Prepared for the 29th Joint Propulsion Conference and Exhibit cosponsored by the AlAA, SAE, ASME, and ASEE, Monterey, California, June 28-30, 1993. F.L. Litvin, N.X. Chen, and C.L. Hsiao, The University of Illinois at Chicago, Chicago, Illinois 60680, and R.F. Handschuh, U.S. Army Vehicle Propulsion Directorate, NASA Lewis Research Center. Responsible person, R.F. Handschuh, (216) 433-3969.

12. DISTRIBUTION/AVAILABILTY STATEMENT

12b. DISTRIBUTION CODE

Unclassified - Unlimited

Subject Category 37

13. ABSTRACT (Maximum 200 words)

Analysis of helical involute gears by tooth contact analysis shows that such gears are very sensitive to angular misalignment that leads to edge contact and the potential for high vibration. A new topology of tooth surfaces of helical gears that enables a favorable bearing contact and a reduced level of vibration is described. Methods for grinding of the helical gears with the new topology are proposed. A TCA program for simulation of meshing and contact of helical gears with the new topology has been developed. Numerical examples that illustrate the proposed ideas are discussed.

\section{SUBJECT TERMS}

Gears; Mechanical drives; Gear teeth

15. NUMBER OF PAGES

17. SECURTY CLASSIFICATION OF REPORT

Unclassified
18. SECURTY CLASSIFICATION OF THIS PAGE

Unclassified
19. SECURTY CLASSIFICATION OF ABSTRACT

Unclassified 


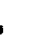

